\title{
Chlamydia trachomatis IgM Antibody Measurement
}

National Cancer Institute

\section{Source}

National Cancer Institute. Chlamydia trachomatis IgM Antibody Measurement. NCI

Thesaurus. Code C100465.

The determination of the amount of Chlamydia trachomatis IgM antibody present in a sample. 